\title{
Bleibt der Pflegeberuf ein attraktiver Ausbildungsberuf?
}

— Unter dem Motto „Die Pflege ist der attraktivste Ausbildungsberuf in Deutschland" präsentierten Vertreter des Arbeitgeberverband Pflege am 11. August in Berlin, rechtzeitig zum Start ins neue Ausbildungsjahr, aktuelle Zahlen des Statistischen Bundesamtes zur Ausbildungssituation. Gleichzeitig warnten sie vor einer generalistischen Ausbildung in der Pflege.

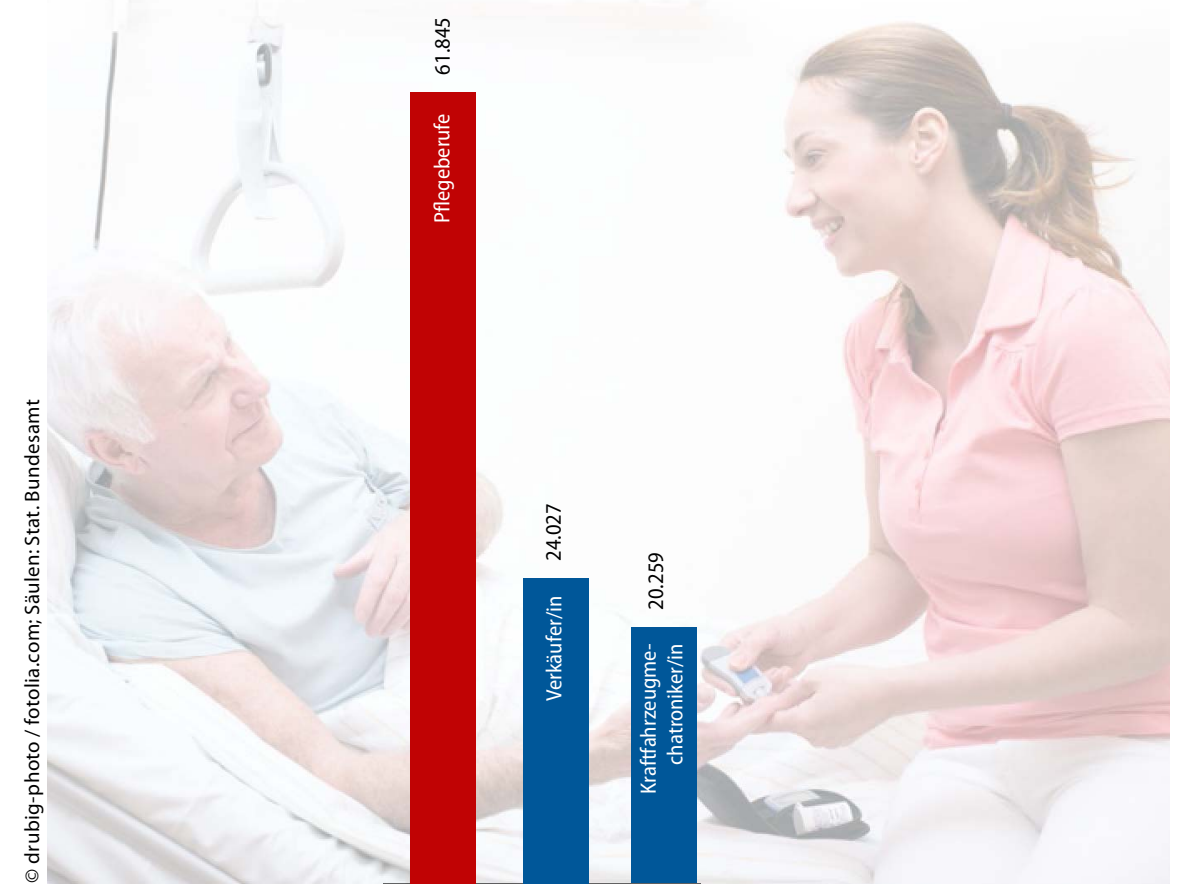

Die Pflege sei seit Jahren der attraktivste Ausbildungsberuf. Positiv zu Buche schlagen langfristig sichere, wohnortnahe Arbeitsplätze, gute Aufstiegsmöglichkeiten und flexibel zu gestaltende Arbeitszeitmodelle. Mit knapp 62.000 neu abgeschlossenen Ausbildungsverträgen im Jahr 2015 (s. Grafik) liege die Pflege deutlich über den Werten anderer Branchen. Der Zulauf zur
Altenpflege habe 2014 sogar erstmals den zur Krankenpflege übertroffen.

Doch der gestiegenen Anzahl Pflegender stehe eine deutlich stärker gestiegene Zahl Pflegebedürftiger gegenüber. Und der vorliegende Gesetzentwurf zur Generalistik drohe die Situation in der Altenpflege zu verschärfen, sagte Verbandspräsident Thomas Greiner. In der Altenpflege seien 56\% der Auszubildenden Hauptschüler, so sein Stellvertreter Friedhelm Fiedler. Die geplante einheitliche Ausbildung von Kranken-, Kinderkranken- und Altenpflegekräften sei deutlich theorielastiger als die bisher getrennten Ausbildungsgänge. Die Menge der Hauptschüler wird die damit gestellten Anforderungen, laut Greiner, nicht schaffen. Das oft geäußerte Argument, die generalistische Ausbildung mache den Pflegeberuf attraktiver, halten Greiner und Fiedler für an den Haaren herbeigezogen. Die Pflegebranche bemüht sich aufgrund der hohen Nachfrage verstärkt um ausländische Pflegekräfte. Auch Flüchtlinge sollen die Möglichkeit erhalten, eine Ausbildung anzugehen. Wer die Ausbildung erfolgreich abschließe, solle dafür ein Bleiberecht erhalten. Man hoffe zudem, dass sich die Politik mit finanziellen Förderprogrammen für Geflüchtete in der Pflege ähnlich engagiere wie beim Handwerk.

(Kk)

www.arbeitgeberverband-pflege.de

\section{Nachgefragt \\ Pflegekammer: Was tut sich in Berlin?}

— Eigentlich hatten die Pflegekräfte in Berlin abgestimmt und sich dabei mehrheitlich für eine Pflegekammer in der Hauptstadt entschieden. Das war im März 2015. Seitdem ist nicht mehr viel passiert. Im September wird Berlin einen neuen Senat wählen. Was ist dann zu erwarten? Welche Partei macht sich für die professionelle Pflege wirklich stark?

Aus Anlass der bevorstehenden Wahlen zum Berliner Abgeordnetenhaus am 18.
September hat die Allianz Pflegekammer Berlin bei den verschiedenen Parteien nachgefragt. Die gesundheitspolitischen Sprecher nahmen Stellung, wie sich ihre Partei die Versorgung der Pflegebedürftigen und die Wahrnehmung der Interessen der Pflegenden künftig vorstellt. Werden sie sich für die Einrichtung einer Pflegekammer Berlin einsetzen und damit das Votum der Berliner Pflegenden von 2015 umsetzen? Unter dem Motto
„Unsere Zukunft? Selbstbestimmt!" hat die Allianz Pflegekammer Berlin auf ihrer website Daten und Fakten zur Errichtung einer Kammer in Berlin zusammengestellt. Ein Blick lohnt sich.

www.berliner-pflegekammer.de 